\title{
SOSYAL YARDIM ZAMMININ ANAYASAYA UYGUNLUĞU SORUNU
}

\author{
Doç. Dr. Merih ÖDEN
}

506 sayili Sosyal Sigortalar Kanununun Ek 24. maddesinin 7.1.1986 günlü ve 3251 saytl Kanunla değişik (a) bendinde, 506 sayılı Kanuna göre iş kazaları, meslek hastalıkları, malûllïk, yaşlılık ve ölüm sigortalarından gelir ve aylık alanlar ile 991 sayılı Kanunla Sosyal Sigortalar Kurumuna (SSK) devredilen sandiklar mevzuatına göre aylık alanlara her ay sosyal yardım zammı ödenmesi öngörülmüşstür.

506 sayılı Kanunun Ek 24. maddesinin öngördiuğü "sosyal yardım zammı" (SYZ), devletin, devlet memurlarına yakacak yardımı ve Emekli Sandığı'ndan aylık alanlara yine sosyal yardım zammı adı altında yaptığı sosyal yardımlara koşut olarak Sosyal Sigortalar Kurumu'ndan (SSK) gelir ve aylık alanlara, sosyal sigorta yardımlarının yetersizliğini bir ölçüde gidermek amacıyla sağladığı ek (munzam) bir sosyal ödeme, yani sosyal yardım türüdür ${ }^{1}$.

Anayasa, herkese sosyal güvenlik hakkınt tanurken, devlete de sosyal güvenliği sağlamak ödevini yüklemiştir (m,60). Bilindiği gibi, sosyal güvenlik sosyal sigortalar, sosyal yardimlar ve sosyal hizmetler olmak üzere başlıca üç yolla gerçekleştirilmektedir ${ }^{2}$. Yasa-

1. 27.10.1977 günltu ve 7/13987 saylı Bakanlar Kurulu Kararı (RG 28.10.1977, S.16098 Mukerrer, s.3-4) gereğjnce SSK'dan gelir ve aylık almakta olanlara sałłlanan "avans" ödemelerini SYZ'ye dönüşțtiren 8.3.1981 günlü ve 2422 sayılı Kanuna ilişkin yasama belgelerine göre, SYZ ile, devlet memurlarına yakacak yardım ve Emekli Sandığı'ndan aylık almakta olanlara SYZ adı altında yapılan ödemeleri SSK'dan gelir ve aylık alanlara da yaymak ve böylece sosyal sigorta emeklilerinin aylıkların bir miktar artırmak amacı güdülmüş̧ür (Bkz. MGK Tutanak Dergisi, C.II, 6.3.1981 günlü 42. Birleşim Tutanağına Bağlı S. Sayısı: 161, s.1, 4-5; C. II, $\mathrm{s.433}, 450-51$ ). Essasen, konuya ilişkin düzenlemelerin gelişimi de aynı amacı ortaya koymaktadır.

2. Bu kavramlar için bkz. Sait Dilik, "Sosyal Gúvenliž̆in Yöntemleri", AÜSBFD, C.XXVI, (Aralik 1971), No: 4, s.74 vd.; Sait Dilik, "Sosyal Yardimlar: Iki Anlaml Bir Terim", AÜSBFD, C.XXXV, (Ocak-Aralık 1980), No: 1-4, s.55 vd.; Sait Dilik, "Sosyal Güvenlik ve Sosyal Hizmetler Arasındaki İlişkiler", AÜSBFD, C. XXXV, 
ma organı da, Anayasanın 65. maddesi uyarına devletin malî kaynaklarının yeterliliği ölçüsünde, sosyal güvenlik hakkının gerçekleştirilmesinde öncelikler, yöntemler ve ölçüler konusunda geniş bir takdir yetkisine sahiptir ${ }^{3}$. O halde, SSK'nın sağladığı sigorta yardımlarını desteklemek amacıyla muhtaç olan sigortahılara sigorta yardımlarına ek sosyal yardımlar sağlanmasının ve bu bağlamda anılan Kurumdan gelir ve aylık alanlara SYZ adıyla ek bir ödemede bulunulmasının, dolayısıyla 506 sayılı Kanunun Ek 24. maddesinin (a) bendinin, amaç ve ilke olarak Anayasa'nun 2. ve 5. maddelerindeki sosyal devlet ve sosyal adalet ilkelerine, 10. maddesindeki eşitlik ilkesine ve 60. maddesindeki sosyal güvenlik hakkına aykırı olmadığını kabul etmek gerekir.

506 sayılı Kanunun Ek 24. maddesinin (a) bendine göre, SYZ ilgililere her ay SSK tarafindan ödenmekte ve bu ödemeler anılan maddenin (1) bendindeki istisnaî durum dışında Kurumun kendi kaynaklarından karşılanmaktadır ${ }^{4} \mathrm{Bu}$ yöntemin Anayasaya uygunluğu konusunu incelerken, öncelikle, sosyal sigortalar sistemi ile Sosyal Sigortalar Kurumunun temel özelliklerine ve bu alanda kanun koyucunun takdir yetkisinin sınırlarına değinmek yararlı olur.

Sosyal sigorta, çalışanlara sosyal tehlikeler (riskler) karşısında sigorta tekniğiyle ekonomik güvence sağlamak üzere kanunla kurulmuş olan bir sosyal güvenlik sistemidir ${ }^{5}$. Sosyal sigorta sistemi, çalışanlar ve işverenlerce ödenen sigorta primlerinin zaman içinde

(Ocak-Aralık 1980), No: 1-4, s.73 vd.; Kenan Tunçomağ, Sosyal Güvenlik Kavramı ve Sosyal Sigortalar, Gözden Geçirilmiş ve Yenilenmiş 5.B., İstanbul 1990, s.6-9; A. Can Tuncay, Sosyal Góvenlik Hukuku Dersleri, 5.B., tstanbul 1992, s.49 vd.; Ali Nazım Sözer, Türkiye'de Sosyal Hukuk, Ankara 1994, s.26 vd.; Ali Güzel-Ali Rıza Okur, Sosyal Givvenlik Hukuku, 4.B., Istanbul 1994, s.451 vd.

3. Yasama organinun sosyal hakları gerçekleştirme yükümlülüğ̈u konusundà bkz. Bülent Tanör, Anayasa Hukukunda Sosyal Haklar, Istanbul 1978, s.293, 359-85.

4. 506 sayılı Kanunun Ek 24. maddesine 20.6.1987 günlä ve 3395 sayılı Kanunla eklenen (I) bendine göre, genel ve katma bütçeli idareler, mahalli idareler, döner sermayeli kuruluşlar ile kanunla ve kanunların verdiği yetkiye istinaden kurulan kuruluşlar ve 233 sayılı Kanun Hükmünde Kararname kapsamma giren teşekküll ve kuruluşlarla bunłarın milessese, bağlı ortaklık ve iştiraklerinden, çalışı̆̆ı̆ı en son kurulus olarak ayrilmak suretiyle kendisine 506 sayılı Kanun hüümlerine göre malû́llüik, yaşlılık veya ölüm aylığı bağlanan kişilere ödenen sosyal yardım zamları, Sosyal Sigortalar Kurumu tarafindan yazılı olarak istendiğinde, bu kuruluşlarca en çok iki ay içinde Kuruma ödenecektir.

5. -Sosyal sigortanın çeşitli tanımlar için bkz. Ali Nazım Sözer, Sosyal Sigorta İlişkisi, Izmir 1991, s.11-13. Ayrica bkz. Tuncay, a.ge., s.13-14; Adil İzveren, Sosyal politika ve Sosyal Sigortalar, 2.B., Ankara 1970, s.161; Dilik, Sosyal Güvenliǧin Yöntemleri, s.80. 
ilgili sosyal güvenlik kuruluşunca işletilerek değerlendirilmesi ve sosyal tehlikelerin yol açacağı ekonomik kayıplann sigorta yardımlarıyla karşılanması esasına dayanmaktadır. 4792 sayılı Kanunun 1. maddesine göre, SSK "iş hayatında türlï hallere karşı ilgili sigorta kanunu hükümlèini uygulamak" amacıyla kurulmuştur. Başka bir anlatımla, SSK'nın temel görevi, iş hayatında sosyal tehlikelere karş 506 sayılı Sosyal Sigortalar Kanunu hükümlerini uygulamak ve hizmet akdine dayanarak herhangi bir işte çalışanlara iş kazalanyla meslek hastalıkları, hastalık, analık, malûlliük, yaşlılık ve ölüm hallerinde sosyal sigorta yardımlan yapmaktır (506 sayılı K.m.1-2).

1961 ve 1982 Anayasaları, devleti sosyal güvenliği sağlayacak önlemleri almak ve sosyal sigorta ve sosyal yardım kuruluşlarını kurmakla ödevli kılmışlardır. SSK, Anayasanın devlete yiuklediği sosyal güvenliği sağlama ödevini sosyal sigorta esaslarına göre yerine getirmek üzere kurulmuş bir sosyal güvenlik kuruluşudur. Kurum, gelirlerinin yalnizca sigortadan yararlananlara aynlmasina karşın, sosyal sigorta sisteminin belirtilen özelliklerinden ötürü, malî ve idarî bakımdan özerk, tüzel kişiliğe sahip bir devlet kurumudur ${ }^{6}$. Sosyal güvenliği sağlayacak teşkilatı kurmus olan devlete düşen ödev ise, esas olarak, kurulu teşkilatın düzenli ve rasyonel çalışmasını ve gelişmesini sağlamaktır ${ }^{\text {? }}$.

Anayasa Mahkemesinin de belirttiği gibi, devlet sosyal sigortaların gerektirdiği düzenlemeleri yaparak ve sosyal sigortacılığın teknik gereklerine uygun hareket ederek, SSK'nin mali yapısının güçlii tutulmasindan sorumludur ${ }^{8}$. Kanun koyucunun da, sosyal sigorta sisteminin gerek ve esaslarına uygun, SSK'nın malî kaynaklarını zaman içinde değerlendirerek gelirlerini arttırmasını, böylece doğacak hakları finanse etmesini ve bu haklardan makûl ölçüler içinde dengeli ve eşit olarak tüm sigortalılanı yararlanmasını sağ-

6. Sosyạl Sigortalar Kurumu ve hukukî yapısı hakkında błzz. Tunçomă̆, age., s.71-72; Gizel-Okur, age., s.129; Tuncay, age., s.85-86. Ayrica bkz. Tankut Centel, "Thirk Sosyal Sigorta Kunumlarının Özerkliği Üzerine Bir Denéme", Idari Hukuku ve flimleri Dergisi, Sarica'ya Armağan, 1982, s.1-3, s.21 vd.

7. "....Devlet, esasen gerekli teşkilatı kurmuştur. Maddede kurulması öngörulen teşkilatun modernleştirilmesini, rasyonel çălışmasını sağlamak Devlet tarafindan gerçekleştirilecektir..." (1982 Anayasasının 60. maddesinin gerekçesi; Türkiye Cumhuriyeti Anayasasi: Komisyon Raporlar ve Madde Gerekçeleri, Ankara 1983, s.106).

8. E. $1990 / 5$, K. 1990/28, k.t. 14.11.1990, AYMKD, S.26, s.489-90; E.1990/28, K.1991/11, k.t. 2.5.1991, AYMKD, s.27, C.I, s.353-54; E.1991/5, K.1992/9, k.t. 18.2.1992, RG 7.5.92, S.21221, s.17. 
layacak kurallar koyması, dolayısıyla aksi yönde kurallar koymaktan özenle kaçınması zorunlưdur'.

Bu durumda, 506 sayıl Kanunla kurulu sosyal sigorta sistemine Ek 24. maddenin (a) bendi ile eklenen SYZ konusunda göze çarpan ilk husus, SYZ'nın niteliği itibariyle sosyal sigorta sisteminin zorunlu kıldığı bir sosyal sigorta yardımı değil, bir sosyal yardım veya sosyal ödeme türü olduğudur. Sosyal sigortalarda, dolayısıyla sosyal sigorta yardımlarında kişilere prim ödemeleri koşuluyla, yani edim-karşı edim esasina göre sosyal tehlikeler karşısında ekonomik güvence sağlanması söz konusudur. Sosyal yardımlar veya sosyal ödemeler ise, yoksul ve muhtaç durumdaki kişilere sosyal gelir sağlamak amacıyla, yani muhtaç olma koşuluyla ve ilgililerin herhangi bir katkısı olmadan yapilan yardımlardır. Bu nedenle, kamu kuruluşlarınca yapılan sosyal yardımlar devlet bütçesinden karşılanırlar ${ }^{10}$. SYZ de prim ödeme karşılığı yapılan bir sigorta yardımı olmayıp, amacı, ödeme koşulları ve hatta adından da anlaşıldığı gibi, devletin tek taraflı olarak sağladığı bir sosyal yardımdır. Bu dunumda, SYZ'nin kendine özgü bir sosyal güvenlik yöntemi olan sosyal sigorta sisteminin temel ilkelerine uymadığı öne sürülebileceği gibi; SYZ'nin sigortalılara Kurumca ödenen gelir ve aylıkların yetersizliğini bir ölçüde gidermek amacıyla öngöriulen, sigorta işleri ve sigorta yardımlarıyla sıkıca ilişkili bir sosyal yardım olduğu, dolayısıyla SSK eliyle sigortalılara SYZ ödenmesinin sigorta sisteminin temel amaçlarına aykırı düşmediği de söylenebilir. Kanımızca, tartışmaya açık olan bu konuda, kanun koyucunun sosyal sigorta kuruluşlarını sigortalılara sigorta yardımlariyla birlikte bu yardımlarla sıkıca ilişkili bazı ikincil ve istisnaî yardımlarda bulunmakla da görevlendirebileceğini kabul etmek ve SYZ ödemelerinin, SSK kaynaklarından karşılanmasının sigorta sistemi ilkelerine ve Kurumun işlevlerine uygunluğu üzerinde durmak doğru olur.

Kuskusuz, SSK'nın sigorta işleri ve sigorta yardımlarıyla sıkıca ilişkili bazı sosyal yardımlanı da sağlamakla görevlendirilebilmesi, Kuruma sigortanın temel özelliği ve varlık nedenini oluşturan sos-

9. Bkz. E. 1989/11, K.1989/48, k.t. 12.12.1989, AYMKD, s.25, s.431; E.1990/5, K.1990/28, k.t. 14.11.1990, AYMKD, S. 26, s.482, 490; E. 1991/5, K.1992/9, k.t. 18.2.1992, RG 7.5.1992, S.21221, s.15, 17; E.1991/23, K.1991/47, k.t. 10.12.1991, RG 13.9.1992, S.21344, s.21-22; E.1972/16, K.1972/49, k.t. 17.10.1972, AYMKD, S. 10 , s. $540-41$.

10. Bu konuda bkz. Dilik, Sosyal Yardımlar, s.55-57, 68-72; Tunçomağ, age., s.6-7, 340; Tuncay, age., s.6*7, 48-50; Güzel-Okur, age., s.10, 451-52. 
yal tehlikenin karşılanması işlevini gereği gibi yerine getirmesini aksatıcı veya engelleyici yükümler yüklenebileceği anlamına gelmez. Başka bir anlatımla, kanun koyucunun SSK'ya, bu Kurumun kendisinden beklenen sigorta işlerini görmesini ve sigorta yardımları yapmastnı aksatıcı veya engelleyici ikincil nitelikte sosyal yardim ödemeleri yüklemekten kaçınması gerekir. $\mathrm{Bu}$, söz konusu sosyal yardımların veya sosyal ödemelerin öngörülüş amaçları kadar, devletin Anayasanın 60. maddesinden doğan SSK'nın malî yapısını güçlï tutma ödevinin de bir gereğidir.

506 sayılı Kanuna göre gelir ve aylık almakta olan sigortalılara her ay SSK tarafindan ödenen SYZ, bu sosyal ödemelerin Ek 24. maddenin (I) bendindeki istisnaî durum dışında Kurumun kaynaklarından karşılanması yöntemi bakımından, yukanda belirtilen ilkelere, dolayısıyla Anayasaya aykın düşmektedir. Bu yöntem, herşeyden önce, SYZ ile güdülen amaçla çelişmektedir. SYZ, SSK'nın esas olarak prime dayalı gelirleriyle sigortalılara sağladığı gelir ve aylıkların yetersizliğini bir ölçüde gidermek amacıyla öngörülmüß̧tiir; ancak, Kurumun her ay emekli aylıklarına ek olarak yapacağ sosyal ödemeleri yine kendi gelirleriyle karşılaması yöntemi benimsenmiştir. Oysa, SSK, sigorta işlerini, yani sosyal tehlikelere karşı sigortalıları koruma görevini gereği gibi yerine getiremiyorsa, esas olarak sosyal sigortanın karşılayacağı tehlikeler için ödenen primlerin oluşturduğu paradan bir kısmımın her ay yapılacak SYZ ödemeleri için kullanılmasının, sosyal sigorta sisteminin temel işlevini oluşturan sigorta işlerinin görüulmesini ve sistemin belkemiğini oluşturan sigorta yardımlarının, bu arada sigortalıların emekli aylıklannın ödenmesini daha da aksatacağı ortadadır.

Öte yandan, SYZ, 506 sayılı Kanuna göre aylık almakta olan bütün sigortalılara her ay ödenen ve bir bakıma niteliği gereği, yani devletçe tek taraflı olarak sağlanan ve ilgililerin maddi katkısına dayanmayan, dolayısıyla primlere yansımayan bir ödeme olduğu için, süratle artış gösteren bir sosyal yardımdır. SSK'ca belirtildiğine göre, SYZ ödemeleri, 1977 'de 750 lira olarak başladığı halde, 15 yıl içinde 1300 katına çıkarak, ayda 975.000 liraya ulaşmış; 19771991 döneminde toplam 11 trilyon lira SYZ ödenmişken, yalnızca 1992 'de 12,1 trilyon lira ve 1993 yllının ilk 4 ayında ise 5,3 trilyon lira emekli aylığına karşlik 6,3 trilyon lira SYZ ödenmiş; SSK'nın aylik ödemeleri içinde SYZ oranı 1980 'de \%17 iken, 1992'de \%49 ve nihayet 1993 'ïn ilk 4 ayında $\% 54$ olarak gerçekleşmiştir ${ }^{11}$. Bu 
veriler, SSK'nın SYZ ödemeleri nedeniyle temelde prime dayalı gelirlerini zaman içinde değerlendirerek sosyal sigorta yardımlarını sürdürme ve doğacak hakları, yani sigorta yardımlarını karșlama olanağını süratle kaybetmekte olduğunu açıkca göstermektedir. Bu durumda, SSK'nın malî kaynaklarının hızla azalmasına yol açan, Kurumun aktüeryal dengesini bozan ve sosyal sigorta ilkelerine göre gelirlerini zaman içinde değerlendirerek temel işlevini gereğince yerine getirmesini giderek tehlikeye düşüren itiraz konusu Ek 24 . maddenin (a) bendinin Anayasanın 60. maddesine aykırı düştüğüne kuşku yoktur.

Burada, 506 sayılı Kanunun Ek 24. maddesine 20.6.1987 günlü ve 3395 sayılı Kanunla eklenen (I) bendinde, kamu kuruluşlarından ve bunların müessese, bağlı ortaklık ve isstiraklerinden ayrılarak emekli olanlara yapılan SYZ ödemelerinin ilgili kamu kuruluşlarınca SSK'ya ödenmesinin öngörülmüş olmasının, (a) bendinin Anayasaya aykırılı̆̆ını gidermeye yeterli olmadığını da belirtmek gerekir. Bu hüküm, bir yandan SYZ ödemelerinin hazinece karşılanmasını öngören 5434 sayılı Emekli Sandığı Kanununun Ek 40. maddesinde 7.5.1986 günlü ve 3284 sayll. Kanunla (m.21) yapılan değişikliğe koşut bir düzenleme getirmek, diğer yandan da, SYZ ödemelerinin SSK'nın mali olanaklarını aşırı zorlaması ve Kurumun işlevlerini yerine getirememesi tehlikesi karşısında, bu ödemelerin kısmen karşılanması ve 1987 yılı itibariyle Kurumun aktüeryal dengesinin daha da bozulmasını önlemek amaçlarıyla getirilmiştir ${ }^{12}$.

Kamu kuruluşlarnndan emekli olanların SSK'dan gelir ve aylık almakta olanların ancak \%30'unu oluşturduklanı dikkate alındığın$\mathrm{da}^{13}$, Ek 24. maddenin (I) bendindeki kuralla $S S K$ 'nın yaptığı SYZ ödemelerinin Kurum gelirlerinde yarattığ eksilmenin yalnızca çok az bir kısmının telafi edilebileceği açıktır. Bu nedenle, anılan (I) bendi hükmü ile güdülen amaçların gerçekleşebileceği kabul edilse bile, bu durum SYZ ödemelerinin Kurumun malî kaynakları, dolayısıyla sosyal sigorta sistemi üzerindeki olumsuz etkilerini gidermeye yeterli değildir. Kaldı ki, Ek 24. maddenin (I) bendinde, SSK'nın kamu kuruluşlarından emekli olan sigortalılara yaptığı

11. Sosyal Yardım Zamm (SYZ) Hakkında Not, s.1-2.

12. Bkz. TBMM Tutanak Dergisi, Dönem 17, C.XXXXIlI, 20.6.1987 gỉnlü 121. Birlesim Tutanağına bağłı S. Sayısı: 586, s.5, 1-2. Ayrıca bkz. Anayasa Mahkemesinin 18.2.1992 günlü, E. 1991/5, K.1992/9 sayılı karan, RG 7.5.1992, s.21221, s.14-16.

13. Sosyal Yardım Zamm (SYZ) Hakkında Not, s.2. 
SYZ ödemelerinin yazılı olarak istendiğinde, bu kuruluşlarca en çok iki ay içinde Kuruma ödenmesi öngörülmüşse de, SYZ karşıllğının ilgili kamu kuruluşlarından zamanında tahsilini sağlayacak ve nihayet her ay peşin olarak yapılan SYZ ödemeleri dolayısıyla sigorta gelirlerinin işletilerek değerlendirilememiş olmasının yarattığı eksikliği telâfi edecek herhangi bir önlem alınmamıştır. Bu nedenle, söz konusu (I) bendi hükmünüun öngörülüiş amaçlarını dahi tam olarak gerçekleştirebileceği kuşkuludur ${ }^{14}$.

Yine, 4792 sayll SSK Kanununun, Kurumun gelirlerini gösteren 19. maddesinin $(F)$ bendine göre, devletin Kuruma genel bütçeden yardım yapması olasılığının varlığı da, 506 sayılı Kanunun Ek 24. maddesinin (a) bendindeki SYZ'ye ilişkin kuralın Anayasaya aykurilığını ortadan kaldırmaz. Bu hükü̈m, gerektiğinde, yani SSK'nın temel görevini oluşturan sigorta işlerini kendi kaynaklanyla karşılayamaması halinde, devletin bu Kuruma doğrudan malî yardımda bulunma yükümlülüğüünü ortaya koymaktadır ${ }^{15}$. Eșasen, devłetin gerektiğinde SSK'ya doğrudan yardımda bulunması, Anayasanın 60 . maddesi uyarinca sosyal güvenliği sağlamakla kendisinin ödevli oluşunun bir sonucudur. Bununla beraber, doğrudan devlet yardımları SSK'nın temel bir gelir kaynağı sayılmaz. Kurumun, sigorta primlerinden oluşan gelir ve giderlerinin kendine yeterli olması asıldır ${ }^{16} .4792$ sayılı Kanunun 19/F maddesi, devletin öncelik-

14. SSK'ca belirtildiğine göre, 1987-1992 döneminde kamu kuruuşlan adına tahakkuk ettirilen 5.5 trilyon lira tutanndaki SYZden yalnızca 600 milyar lira tahsil edilebilmiştir (Sosyal Yandım Zammı (SYZ) Hakkında Not, s.2).

15. Bu bend 4792 sayılı Kanuna ilişkin tasanya TBMM Genel Kurulu'nđaki görüşmeler sırasında verilen bir önergenin ilgili Komisyonca, "...Kanunun bünyesinde Hüküimet yardımı esas olarak derpiş edilmediğinden dolayı bütçe formülünde böyle bir gelirin zikir ve beyanina komisyonumuz hacet görmemişti. Maahaza her ihtimale karşı bunun da maddenin (E) bendi olarak, genel bütçeden yapılan yardımlar, şeklinde ilave edilmesinde komisyon bir mahzur mülâhaza etmiyor ve bilâkis fayda millâhaza ediyor." denilerek benimsenmesi üzerine eklenmiştir (Bu konuda bkz. TBMM Zabst Ceridesi, Devre 7, C.XIX, s.67-68, 72). Burada, Anayasa Mahkemesinin de, anulan 19/F bendini ve Emekli Sandığı Kanunu ile Bağ-Kur Kanunundaki benzer hüükïmlerì aynı yönde youmladığinı belirtmek gerekir. Bkz. E. 1972/16, K. 1972/49, k.t. 17.10.1972, AYMKD, S.10, s.540; E. 1990/27, K.1991/2, k.t. 17.1.1991, AYMKD, s.27, C.I, s.139; E.197.1/19, K.1971/61, k.t. 29.6.1971, AYMKD, s.9, s.564; E.1971/ 44, K.1972/29, k.t. 6.6.1972, AYMKD, s.10, s.442, 440; E. 1981/2, K. 1981/21, k.t. 5.5.1981, AYMKD, S.19, s.99.

16. E.1971/19, K.1971/61, k.t.29.6.1971, AYMKD, s.9, s.564; E.1971/44, K.1972/29, k.t. 6.6.1972, AYMKD, s.10, s.440-442. Nitekim, bugline dejin SSK'ya hiç devlet yardımı yapilmamıs olması da kayda değer (Sosyal Yardım Zammı (SYZ) Hakkında Not, s.2). Ayrica bkz. Tunçomağ, a.ge., s.88-89, 152-53; Tankut Centel, "Türkiye'de Sosyal Sigortalara Devlet Yardum Uzerine Bir Deneme", Idare Hukuku ve flimleri Dergisi, Y 119,1988, s.1-3, s.40-42. 
le sosyal sigorta sisteminin gereklerine ve sosyal sigorta ilkelerine uygun düzenlemelerle SSK'nın malî yapısını güçlü tutma sorumluluğunu ortadan kaldıran bir hüküm değildir. Bu nedenle, devletin SSK'ya sosyal sigorta sisteminin zorunlu kılmadığı bazı sosyal yardım ödemeleri yüklemesi, Kurumun kaynaklarının zamanla tükenmesi tehlikesine karşı gerekli ve yeterli önlemleri almaması ve sonuçta Kurum temel işlevini yerine getiremez hale düşünce, Onu devlet yardımıyla ayakta tutmaya çalışması, hem bu hükmün konuluş amacına, hem de sosyal sigorta sisteminin kuruluş amacına aykiri olur ${ }^{17}$.

Şunu da belirtmek gerekir ki, SSK tarafından ödenen SYZ'nin anılan 19/F maddesi işletilerek genel buitçeden yapılacak yardımlarla karşılanması, ortaya başka Anayasaya aykırıkı sonunları çıkaracağı için, isabetli bir yöntem olarak da görünmemektedir. Bir kere, SSK'ya 4792 sayll Kanunun 19/F maddesine göre yapılacak doğrudan devlet yardımlan, Kurumun kaynaklarındaki eksilmeler ölçüsünde değil, Anayasanın 65. maddesine göre devletin malî kaynaklarının yeterliliği ölçüsünde olacaktır. Bu đurumda, SSK'ya ileride yapılması olası devlet yardımını, halen prim ödeyen sigortalıların hak ve menfaatlerinin korunması bakımından yeterli bir güvence olarak değerlendirmek güçtür. SSK'ca ödenen SYZ'lerin sonradan sürekli olarak genel bütçeden yapılacak yardımlarla, dolayı̣ıyla sosyal sigorta kapsamı dışında tutulanlardan vergi adı altında sağlanan paralardan karşılanacağı kabul edildiğinde, SYZ, bu kez bu sosyal yardımdan yararlananlar, yani yardımın öznesi bakımından Anayasanın 10. maddesindeki eşitlik ilkesine, hatta 2. ve 5. maddelerindeki sosyal adalet ilkesine aykmi düşer. Her ne kadar, devlet sosyal hak özneleri konusunda geniş bir takdir yetkisine sahip ise de, bu takdir yetkisinin sınırsız olmadığını, dolayısıyla, zaten sigorta yardımlarıyla asgari ölçüde ekonomik güvenceye kavuşmuş olan az sayıdaki sigortalının sürekli yardımlarla, toplumun sosyal ve ekonomik bakımdan daha yoksul ve muhtaç durumdaki kesimleri karşısında öncelikle korunmasının, sosyal adalet ve eşitlik ilkeleriyle çelişeceği de söylenebilir ${ }^{18}$. Ayrıca, SSK'nın yaptığı SYZ ödemelerinin genel bütçeden sürekli olarak yapılacak doğrudan devlet yardımlarıyla karşılanması, Emekli Sandığı ile SSK'dan aylık al-

17. Anayasa Mahkemesi'nin de benzer yaklaşımla verdiği iptal kararlarına ömek olarak bkz. E. 1971/19, K.1971/61, k.t. 29.6.1971, AYMKD, s.9, s.564-65; E.1972/16, K.1972/49, k.t. 17.10.1972, AYMKD, s.10, s.540-42.

18. Benzer görüş, Tunçomă̆, age., s.88; Centel, Türkiye'de Sosyal Sigortalara Devlet Yardımı, s.42-43. 
makta olanlar arasında eşitlik ilkesine aykırı olarak farklı işlem yapilması sonucunu da doğurur ${ }^{19}$.

Öte yandan, sosyal güvenliği sağlamak öncelikle bir kaynak, dolayısıyla kaynak yaratma sorunudur. Devlet, malî kaynaklarının yeterliliği ölçüisünde tek taraflı olarak yoksul veya muhtaç duruma düşen kişilere sosyal yardım yapabilir. Ancak, devletin kendi gelirlerinden sosyal güvenlik alanına yeterli kaynak aktarmadan, SSK'ya SYZ gibi kapsaml ve sürekli sosyal ödeme yükümlülüikleri yuiklemesi, sosyal sigortacılığın özelliği gereği malî bakımdan özerk bir tüzel kişi olan Kurumun malvarlığının münhasıran sigorta işlerine tahsis edilmesi yerine, sosyal amaçlı kamu harcamalarının finansman kaynağı olarak kullanılması sonucunu doğurur. Bu durumun, Anayasanın 60. ve 65. maddelerinin özüne aykın düşeceği açıktır. Nihayet eklemek gerekir ki, SSK'ca yapılan SYZ ödemelerinden sigortalılann yararlanmakta oluşu da, devletin SSK'nın malvarlığına el atmasını haklı kılmaz ${ }^{20}$.

19. Genel olarak bkz. Tungoma , age., s.88. Burada, Emekli Sandığı'ndan aylık alanlara ödenen SYZ'yi düzenleyen Ek madde 40 'n 30.6.1989 günla ve 375 sayll KHK ile (m.32/b-c) yitirirlükten kaldınlarak, SYZ yerine taban ayliğ ve kıdem aylığı tutarnda bir miktann emeklj aylıklarına eklenmesi esasınun benimsendiğine ve daha sonra 6:1.1992 günlí ve 476 sayılı KHK ìle (m.1) eklenen Ek 70. maddeye göre iştirakçilere ödenen taban aylığ ve kıdem aylığı tutarlarnın da kesenek ve karşılığa tabi bir odeme olarak kabul edildighine dikkat cekmek gerekir.

20. Sosyal sigorta kurumlarının ozzerkliž i ile sosyal sigorta fonlanmın amaca uygun kullanım arasındaki iliskj konusunda aynca bkz. Centel, Türkiye'de Sosyal Sigortalara Devlet Yardım, s.40, 44-45; Centel, Tïrk Sosyal Sigorta Kurumlarinın Ozerkliği, s.32-33. Öte yandan, 506 sayıl Kanunun Ek 24. maddesinin (a) bendinin Anayasaya aykırılğı karşısında, (I) bendi de hukukî temelden yoksun kalmaktadır. Ayrıca (I) bendi huikmininün, kamu kuruluşlanndan aynlarak emekli olan biri Emekli Sandjğı'ndan, diğeri SSK'dan aylik almakta olan iki grup arasında prim veya kesenek karşlığı olmayan SYZ ödemelerinden yararlanma bakımından ve kamu 'kuruluşlan, özellikle KIT'ler ile özel sektör kuruluşlar arasında SYZ karşılığın SSK'ya öđeme yưkkïmlültü̆ł bakımından yarattı̆̆ 1 farklılıkların Anayasanın 10. maddesindeki eşitlik ilkesini zedelediğine de işaret edilmelidir. Anayasa Mahkemesi, Ek 24. inaddenin (I) bendinde yer alan "...ve iştiraklerden..." ibaresini Anayasanın 10. ve 49. maddelerine aykın bulmamıştır. Ancak Mahkeme, eşitlik ilkesi yönùnden incelemede, esas olarak, "iştirakler"in SYZ ödemelerini karşılama yükïìmii bakımundan kamu kuruluşu mu, yoksa özel sektŏr kuruluşu mu olduğu konusu üzerinde durmuştur. Bkz. E. $1991 / 5$, K.1992/9, k.t. 18.2.1992, RG 7.5.1992, s.21221, s.11-22. 